\title{
De la Bella Durmiente a la durmiente disecada: la reficcionalización de Brunilda en Galaor de Hugo Hiriart
}

\section{From Sleeping Beauty to Stuffed Sleeper: The refictionalization of Brunilda in Hugo Hiriart's Galaor}

\author{
Julio Enrique Macossay Chávez \\ Universidad Nacional Autónoma de México \\ makofiend@hotmail.com
}

\begin{abstract}
En este artículo el autor muestra la manera en que dos motivos tradicionales que forman parte de nuestro imaginario cultural, como lo son la entrega de los dones y el letargo de "la bella durmiente del bosque", pasan por un proceso de reficcionalización medievalizante cuando son insertados en una obra caballeresca moderna, en este caso, Galaor de Hugo Hiriart.
\end{abstract}

Palabras Clave: motivos, literatura mexicana delsigloxx, caballería, Galaor, intertexualidad.

In this article the author shows how two traditional motifs that form part of our cultural imaginary, like the offering of gifts and the slumber of the "sleeping beauty of the forest", go through a process of medievalizing refictionalization when they are inserted in a modern chivalric work, in this case, Hugo Hiriart's Galaor.

KEYWORDs: Motifs, mexican literature of the $20^{\text {th }}$ century, chivalry, Galaor, Intertextuality.

FECHA DE RECEPCIÓN: 04/12/2016

Fecha DE ACEPTACiÓN: 26/01/2017

$I^{\prime \prime}$

talo Calvino, al hablar de Tirante el Blanco, dijo que:

Desde sus primeras páginas la primera novela de caballería de España parece querernos advertir que todo libro de caballería presupone un libro de caballería anterior, necesario para que el héroe se haga caballero. "Tot l'ordre és en aquest llibre escrit”. De este postulado se pueden extraer muchas 
conclusiones, incluso la de que tal vez la caballería nunca existió antes de los libros de caballería, o que directamente sólo existió en los libros ("Tirant lo Blanc", 63).

Esto puede aplicarse a la materia caballeresca hispánica del siglo xx porque está conformada por obras que, en mayor o menor medida, tienen a las novelas de caballerías como base de la ficcionalización —en el sentido más amplio del género-, ya sea a una, a varias o a un ciclo; por ejemplo, si pensamos en El caballero inexistente, de Italo Calvino, la obra parte del llamado ciclo carolingio, mientras que Galaor, de Hugo Hiriart, del Amadís de Gaula, y El rapto del Santo Grial, de Paloma Díaz-Mas, del ciclo artúrico. Sólo que se debe aclarar que en este caso no son imitaciones puntuales del "libro de caballería anterior", sino que toman algunos elementos y se les reinterpretan a partir de la óptica personal de cada autor.

En el caso particular de la novela del mexicano, como bien apunta Aurelio González, "Galaor parece ser un relato situado entre el cuento de hadas infantil y la novela de caballerías”. Puntualizando: se puede decir que el autor reficcionalizó el cuento "La Bella Durmiente", pero lo situó en un texto cuya "estructura [... es similar, en líneas generales, al modelo típico de la novela de caballerías” (González, "La vehemencia”, 208). Es inevitable que se piense en la protagonista del ya mencionado relato tradicional y que se aprecien todas las diferencias que hay entre ella y Brunilda, "La durmiente disecada". El presente trabajo mostrará cómo Hiriart reficcionalizó a "La bella durmiente del bosque" para la creación de la princesa que tendrá que rescatar el joven Galaor, ajustándola al mundo caballeresco en el que se desarrolla la obra Para ello se analizará el bautizo de la princesa y su transformación en "La durmiente disecada".

Lo primero que debe hacerse es definir el concepto de ficcionalización. Éste apunta a que "un texto literario no reproduce objetos, ni crea objetos en el sentido descrito" (Iser, "La estructura apelativa”, 102) sino que los ficcionaliza, debido a que "la realidad de los textos es siempre tan sólo la constituida por ellos, y con ello, es una reacción a la realidad" (102). No sólo pasan por este proceso los objetos del mundo real, sino que existen textos que hacen lo mismo con otras obras literarias o elementos de éstas.

Existen dos tipos de ficcionalización: el primero consiste en tomar un referente de la realidad y trasladarlo a un texto; mientras que el segundo, que es la ficcionalización compleja o reficcionalización, consiste en tomar un referente ya ficcional y cambiarle el sentido para que encaje en la realidad textual de una obra distinta. Aunque cabe aclarar que para hacer esto, en una obra caballeresca como ésta, el mecanismo más utilizado es la medievalización de 
los referentes, en otras palabras, la ficcionalización de ellos a partir de lo que el autor interpreta como la visión medieval de la realidad para que encajen en el mundo textual de la novela. Debido a que este proceso se hace a partir de lo que el autor cree que es lo medieval, se ficcionaliza en mayor medida con base en estereotipos, aunque esto varía de escritor en escritor.

Brunilda, en Galaor, es una reficcionalización de la protagonista del cuento La bella durmiente del bosque, de Charles Perrault, pero existen varias razones que complejizan al personaje. En primer lugar, su nombre remite a un personaje de la mitología germano-escandinava que en las narraciones míticas suele presentarse como una skjaldmö (virgen escudera) o valquiria. Como bien apuntan Hernández Cuevas y Zepeda Soto, un texto que es importante referir al hablar de la Brunilda de Hiriart es la Völsungasaga — Saga Volsunga_, en la que aparece la valquiria Brynhild. El texto:

cuenta la historia [de] que Brunilda, por no rendir obediencia a Odín, éste hizo que la valkiria se pinchara con la espina del sueño; por esto, nunca más volvería a repartir gloriosas victorias a los valiente guerreros. Además, estaba condenada a contraer nupcias, por lo que la valkiria, ofendida, juró que no se casaría con nadie que conociera el miedo. $\mathrm{Y}$ así, fue colocada en una montaña bajo el hechizo del sueño y rodeada por un aro de fuego, hasta donde sólo un héroe temerario podría acceder y despertar a la aguerrida pero hermosa valkiria (Hernández Cuevas y Zepeda Soto, “Galaor” a lomos, 49-50).

Lo anterior evoca al motivo tradicional de la joven que se pincha el dedo y por ello entra en un estado de letargo. Es muy probable que de la figura mitológica Brunilda se derivara ese motivo; sin embargo, hay que tomar en cuenta que la Brunilda de Hiriart, como señalan Hernández y Zepeda, se fundamenta en La bella durmiente del bosque (La belle au bois dormant) de Perrault (Hernández Cuevas y Zepeda Soto, "Galaor" a lomos, 49-50); si bien ésta es la versión más conocida de dicha historia tradicional, lógicamente no es la única, ${ }^{1}$ aunque es probable que la base de la ficcionalización de Brunilda se encuentre en dicho cuento. En el personaje de Hiriart se encuentran dos motivos ${ }^{2}$ de la variante de

\footnotetext{
${ }^{1}$ La historia fue recogida por primera vez bajo el título Sole, Luna, e Talia por Giambattista Basile en 1634. Posteriormente, la variante más conocida de este cuento es de Charles Perrault, La Belle au bois dormant. Del resto de las variantes destacan la de los hermanos Grimm en 1812 y la versión publicada por Italo Calvino en su libro Fiabe Italiane en 1956.

${ }^{2} \mathrm{Si}$ se desea ver la problemática referente a los motivos caballerescos, véase, Luna Mariscal, "Índice de motivos de las historias caballerescas del siglo Xvi: catalogación y estudio",
} 
Perrault: el de los dones ${ }^{3}$ y el de la bella durmiente. Hay, además, otros elementos puntuales, como el hecho de que los dones sean entregados por jóvenes hadas — siete en el caso de Perrault, cuatro en el caso de Hiriart—, así como que en ambas obras exista un hada vieja que no haya sido invitada y sea la culpable del letargo de Brunilda. Sin embargo, Hiriart retoma este argumento y lo ajusta a una realidad textual caballeresca. Por tanto, debe tenerse presente todo lo anterior para analizar el proceso de ficcionalización de Brunilda.

\section{EL BAUTIZO: LA ESPERPÉNTICA TRANSFORMACIÓN DE BRUNILDA TRAS RECIBIR LOS DONES}

90 El bautizo de Brunilda y la entrega de dones nos remiten a la escena análoga de La bella durmiente del bosque. Esto se puede inferir porque no en todas las variantes del cuento existe el bautizo, el cual representa una particularidad bastante interesante: un sincretismo entre el imaginario cultural y el cristianismo, es decir, entre lo maravilloso y lo cristiano y, por ende, lo maravilloso cotidiano tan propio de la Edad Media y de las tradiciones presentes en el folclor. Gracias a este sincretismo es que existen hadas en un bautizo, cosa que en el cuento de Perrault se justifica diciendo simplemente: "on donna pour Marraines à la petite Princesse toutes les Fées qu'on pût trouver dans le Pays (il s'en trouva sept), afin que chacune d'elles lui faisant un don, comme c'était la coutume des Fées en ce temps-là, la Princesse eût par ce moyen toutes les perfections imaginables" ("La belle", 97).

En Galaor el autor da un mayor realce al bautismo al mencionar la fiesta popular que conlleva, describiéndola de una manera hasta cierto punto medievalizante, sin dejar fuera los elementos que él considera representativos de este tipo de eventos en dicho periodo:

347-359; "Aproximación al estudio de las historias caballerescas breves a partir de los motivos folclóricos", 457-469; "Problemas teóricos y metodológicos en la elaboración de un índice de motivos folclóricos de las historias caballerescas del siglo Xvi”, 313-325 y "De la metodología o la pragmática del motivo en el índice de motivos de las historias caballerescas breves”, 127135; y Bueno Serrano, Índice y estudio de motivos en los libros de caballerías castellanos (15081516); "Aproximación al estudio de los motivos literarios en los libros de caballerías castellanos (1508-1516)”, 95-113 y “Motivos folclóricos y caballerescos en los libros de caballerías castellanos", 83-108.

${ }^{3}$ Éste se encuentra en textos como La chanson d'Ogier, obra del siglo XIV en la que seis hadas, incluyendo a Morgana, le otorgan dones al protagonista recién nacido. 
Las fiestas del bautismo de la princesa deberían recordarse por su magnificencia y prodigalidad. Músicos de afinación perfecta y muy alta inspiración, asistirían con pesados instrumentos de bellos laberintos dorados; y acudirían pintores, escultores, orfebres, alfareros, a perpetuar esplendores en joyas, en muros, en mármoles y jarrones; y no faltarían cómicos, ni amaestradores de monos, ni remedadores de pájaros y fieras, ni acróbatas descoyuntantes y trúhanes y jugadores y poetas y logreros; se contemplarían silenciosos combates entre peces de colores y se derramaría la multitud estridente disfrazada entre elefantes y cocodrilos. Abiertos estaban los graneros atestados, los barriles llenos, los potreros y corrales, vacas, cerdos, gallos y carneros bien cebados y muy apacibles. En el orbe pulcramente dispuesto de la catedral, todo estaba en su orden (Galaor, 13).

Después de las fiestas, aparecen las hadas. En ese punto Hiriart decide no seguir el tópico de la numerología y presenta cuatro hadas en vez de las siete de la versión de Perrault. Estas hadas hacen entrega de los dones, pero lo hacen de una manera mediavalizante y formulaica, lo que incluye la utilización de epítetos:

Habló entonces la mayor de las hadas, llamada As de Copas, y su voz recordó el jadeo de una corza:

"Brunilda bienaventurada, madre de reyes y de arqueros: séate concedido el don grave de la mucha inteligencia para que sean tus amigos los libros y las buenas razones."

Habló la siguiente, llamada Sota de Bastos:

"Brunilda bienquerida, madre de reyes y de astrónomos: séate concedido el don sonriente de la mucha bondad para que sean tus amigos los afligidos [sic.] y tuyas las acciones comedidas."

Habló la llamada Tres de Oros:

"Brunilda bienamada, madre de reyes y de cazadores: séate concedido el don cadencioso de la suntuosa voz musical para que sean tus amigos todos los medidos deleites del sentimiento."

Habló la más niña, llamada Seis de Espadas:

"Brunilda biendeseada, madre de reyes y de teólogos: séate concedido el don fluyente de la elocuencia para que sean tus amigas todas las gentes y tus palabras correctamente dispuestas" (Galaor, 12).

Tal como afirma Colón, "los dones regalados a la princesa en demasía son: inteligencia, bondad, voz musical y elocuencia, prácticamente, los mismos que en el cuento original" (Los elementos, 20). Lo interesante es que para 
reficcionalizarlos Hiriart utiliza la hipérbole, ya que lleva al extremo la idea de los dones, dado que si bien las hadas querían que Brunilda fuera "alguien de excepción: de muchas luces, amiga de libros y de buenas razones, de gran comedimiento y bondades infinitas, maestra en música y en el arte de la elocuencia” (Corral Peña, "La decepción”, 156) lo que en verdad consiguen es que la bebé tenga todas estas habilidades desde la cuna. Es decir, hay una transformación psicológica y hasta filosófica que se manifiesta en sus primeras palabras:

Cadenciosa como el andar de leona joven, melodiosamente nítida como flauta solitaria, espectacular y sonora como mil arpas angelicales, así retumbó en la catedral la voz de la princesa, entonada desde la cuna, cuando terminó de hablar la más niña de las hadas $[\ldots]$

92 Júpiter rey, duque Apolo, acortad mi desventura. ¡Ay señorita Artemisa!, diosa y castísima doncella, a tu devota líbrale de torturas, a la más niña de tus siervas, redímela del penurioso sufrir. ¡Ay Santa Cecilia!, señora de la música, levántame que doblegada vivo ignorante: ¿quién soy? ¿por qué soy castigada? Los pequeños recuerdos difusos, efímeros con luz de amanecer ilustrados, no son míos; si culpable padezco dolores, malandanzas y antojos no almaceno; si soy castigada, no sé de las perfectas remembranzas que hacen sonreír en la soledad a las imprudentes y feroces. ¿Dónde maldades practiqué? Si llorando despierto ¿cuándo dormí? ¿Quién en mí su furia deposita? ¿Quién desvía su misericordia? ¿Por qué los poderosos no escuchan mis lamentos? Triste ignoro mi habitación y naturaleza; mis manos vuelan por mis oídos locas, febriles, incontrolables como insectos y mis piernas potros son que corren a ninguna parte; mis ojos sólo conocen vagos colores y sombras amenazantes. ¡Sufro! ¡Sacadme de aquí! ¡Decidme qué soy pues tanto padezco! ¡Almas comedidas, ayudadme!" (Galaor, 13-14).

Así, Brunilda tiene una voz que envidiarían algunos cantantes de ópera y un gran entendimiento que por supuesto la hace sufrir. En cierta forma la amplificatio radica en que esos dones se manifiestan inmediatamente, en lugar de hacerlo cuando ella fuera más grande. Para que esto ocurra es necesario que haya una manifestación en el plano físico, por lo que se altera el cuerpo de Brunilda para que todos los dones sean posibles, lo que le da una apariencia esperpéntica:

Por acción de los dones, la princesa habíase metamorfoseado: su cabeza, por guardar inteligencia había crecido desmesuradamente; los rasgos antes 
armoniosos de su cara, eran ahora los de un desapacible batracio; el cuello de incomparable cantora, era ancho y vigoroso como de luchador turco; los brazos y piernas de laudista consumada, eran musculosos y blancuzcos semejantes a los del discóbolo de mármol (Galaor, 16-17).

En otras palabras, Hiriart reficcionaliza estos dones haciendo que sean hiperbólicos, lo cual provoca una manifestación física en la princesa, quien sufre una inversión carnavalesca: pasa de ser una bebé de bellas facciones - que luego sería una bella dama de la que se enamorarían reyes en las variantes del cuento tradicional - a "una horrenda masa de carne y pelos, un monstruo enano" (Galaor, 16). Lo anterior se convierte en una parodia de la versión de Perrault, ya que en ésta se le otorgan los dones para que tenga toda clase de perfecciones, mientras que en la novela de Hiriart los dones entregados a Brunilda tienen una expresión psicológica, filosófica, fisiológica y física en comparación con el cuento tradicional donde simplemente se asume que la princesa los posee y por ende se le da el epíteto de "La bella durmiente del bosque".

\section{ENTRE LO MÁGICO Y LO COTIDIANO: LA DURMIENTE DISECADA}

En Galaor el elemento cuya reficcionalización es medular para la trama es el motivo de la joven dormida por un encantamiento. En los cuentos recopilados por Perrault y los hermanos Grimm una de las hadas no le concede un don a la princesa para utilizarlo posteriormente con el fin de salvarla de la maldición que presiente que le lanzará el hada que no fue invitada. Por su parte, en Galaor, después de que a Brunilda se le conceden los dones decide pedir ayuda. Quien aparece al rescate es un hada vieja: "Sota de Espadas, hada conocida en un tiempo como Morgana" (Galaor, 15). De esta manera, Hiriart fusiona a ambos personajes: al hada que no es invitada y a la que decide contrarrestar el mal de ésta, aunque también lo hace con un ser del imaginario medieval que pertenece a la Materia de Bretaña y en específico al ciclo artúrico: el hada Morgana, ${ }^{4}$ con lo cual se medievaliza al personaje del cuento

\footnotetext{
${ }^{4}$ Morgana como hada es una de las más conocidas de la época medieval, e incluso su nombre sirve como referencia para la clasificación de textos de tipo morganiano, aunque también los hay de tipo melusino, como se mencionó anteriormente; de ahí que resulte lógico, hasta cierto punto, que Hiriart aluda a ella para insertarla en Galaor. "Su origen literario se atribuye a
} 
tradicional. Pero lo contrario puede ser dicho; es decir, que Hiriart reficcionaliza a Morgana al otorgarle los atributos definitorios del personaje del relato tradicional, como lo demuestran sus primera palabras: "Soy Sota de Espadas, hada conocida en un tiempo como Morgana, y quisiera saber por qué no se me invitó al bautismo y a la donación" (Galaor, 15).

También se puede decir que hay una inversión de términos en cuanto que en Hiriart son las hadas quienes otorgan los dones que afectan a la joven de manera negativa, "no sólo la transformaron en su aspecto físico, sino que la hicieron entrar al mundo de la conciencia por una puerta falsa, constituyéndose en un ente paradójico: de suma inteligencia, pero de ignorancia abismal”(Corral Peña, "La decepción”, 156), mientras que es el hada vieja y sabía la que la socorre a través del "sueño de la disecación".5 Esto otorga un rasgo 94 paródico, ya que una de las dicotomías de la novela es la inexperiencia de la juventud contra la sabiduría de la vejez. ${ }^{6}$ Esto puede observarse en el hecho de que Sota de Espadas sea la mentora de las jóvenes hadas que erraron por culpa de la inexperiencia, puesto que como ella señala:

Mil veces dije, aconsejé, ordené que el trabajo y la construcción que no se comprenden cabalmente en sus causas y efectos consecuentes, no debe jamás emprenderse y levantarse. Las cartas se tiran sólo en gobernada y sabia mesa. Pero, en vano mencioné deformidades, monstruosidad, desórdenes y fealdad. En vano señalé que la magia y el orden de la naturaleza sutilmente se traman $\mathrm{y}$ tejen, se retuercen y anudan formando el tapiz santuario de nuestra operosa tarea. En vano: estaban ustedes para escucharme (Galaor, 17).

De lo anterior puede inferirse que en Galaor las hadas donadoras son reficcionalizadas, al ser convertidas en hadas jóvenes, lo cual también se puede notar por el epíteto "las magas niñas" (Galaor, 13), debido a que esto es el catalizador de que aquí tengan una función contraria a la del relato tradicional. Gracias a este cambio de papeles, se transforma la causa del letargo así como su intención, ya que en el cuento éste es la manera en que se suaviza

Geoffrey de Monmouth, quien la menciona por primera vez en la Vita Merlini — hacia 1148_al hablar de la Ínsula Pomorum, isla de los frutos o isla afortunada” (Hernández Cuevas y Zepeda Soto, "Galaor" a lomos, 32). Véanse también pp. 31-36.

${ }^{5}$ Aquí hay que recalcar que en el imaginario cultural también el personaje de Morgana tiene un rol antagónico, como se puede notar desde Le Morte d'Arthur, de Sir Thomas Malory, hasta en textos más modernos como The Acts of King Arthur and His Noble Knights (1975), de John Steinbeck, y por ello se vuelve más notorio que aquí ese personaje tenga un rol benigno.

${ }^{6}$ Esto a su vez se debe a que esta novela es una novela de formación. 
el "mal regalo" de la muerte anunciada, mientras que en Galaor no hay un hechizo mortal lanzado en venganza por un desagravio, sino que es la simple inexperiencia la que causa el mal. Es probable que Sota de Espadas haya decidido salvar a Brunilda al haber escuchado su llamado de auxilio, pero también para resarcir "los dones en mala hora regalados" (Galaor, 17) por las jóvenes e inexpertas hadas. A causa de esto, y en contraste con el cuento tradicional, el hada en su posición de mentora las castiga transformándolas en naipes, aunque paradójicamente ella misma tiene nombre de naipe.

Lo más interesante de esta reficcionalización es que en el cuento tradicional se duerme a la princesa para salvarla de la muerte haciendo que sólo tenga que dormir por cien años, mientras que Hiriart hace que Brunilda sea la que pida al hada que acabe con su vida, ${ }^{7}$ mas "Sota de Espadas da la posibilidad de perder los nefastos dones tan gratuitamente recibidos y recobrar su imperfecta normalidad, y ya que se trata, al fin y al cabo, de una 'bella historia de amor y muerte', como diría el autor múltiple de Tristán e Iseo, el remedio para volver a la normalidad será el amor" (González, "La vehemencia", 215). La opción que la vieja hada le otorga a Brunilda es la disecación: "ofrezco dormirla en el sueño profundo: propongo que Brunilda, la niña, sea por mí disecada. La taxidermia y sus agujas son la única salvación del dolor, porque es la disecación el humano recurso que puede enfrentarse victoriosamente a la magia" (Galaor, 18). Es notable que ése sea el recurso para salvarla en la novela, porque:

[las] artes taxidermísticas, [no son] nada propias para un hada tan poderosa como ella, pues, al echar mano de "agujas, vigorosos hilos de colores, cuencos, retortas, sustancias diversas y un caldero", recordamos que no son precisamente las hadas las que recurren a estos utensilios para sus labores mágicas. De este modo, observamos que Hiriart acude a la figura de la Morgana hechicera más que a la de hada (Hernández Cuevas y Zepeda Soto, "Galaor" a lomos, 37). ${ }^{8}$

El hecho de que se visualice una Morgana hechicera ratifica la medievalización del personaje, aunque se debe notar que Hiriart recurre a elementos relacionados con la imagen estereotípica de la bruja: "cuencos, retortas, sustancias diversas y un caldero", y no a elementos relacionados con la figura de

7 "Nada pido, señora de razones esmeradas, sino que termine mi sufrir. Si, como decís, sobrecargada estoy de benevolentes maleficios, volvedme señora al sueño oscuro de donde broté; haced, encarezco, mi vida, breve tránsito" (Galaor, 18).

${ }^{8}$ Aunque debe destacarse que los hilos y en sí el tejido es algo más propio de los personajes de los cuentos tradicionales que de las brujas medievales. 
Morgana. Pero lo notable es que se reficcionalice el contrahechizo del cuento tradicional con un "humano recurso" que en este caso es la disecación, lo cual le otorga a Brunilda su epíteto más importante: "La durmiente disecada", que claramente hace alusión a "La bella durmiente del bosque", aunque Hiriart destaca que desde la donación Brunilda no sea bella, en contraste con la joven del cuento tradicional. Por eso es que a la princesa no se le otorga ese don, sumado al hecho de que sea convertida en "obra maestra de la taxidermia" (Galaor, 20), con lo cual ratifica que se está ante una parodia del personaje del cuento de Perrault. Lo anterior se realza gracias a la descripción carnavalesca de la bebé disecada: "Sota de Espadas la disecó de manera que parecía conversar o cantar, posición que la deslucía un poco confiriéndole apariencia de cosa gesticulante y viva, pero en mineral quietud" (Galaor, 22). Esta cosi-

96 ficación de Brunilda contrasta con la joven bella que duerme en una torre en el bosque de la versión de Charles Perrault.

Otro elemento que Hiriart trastoca es la fórmula del encantamiento, porque si en el cuento tradicional el hada dice "la princesa se clavará la mano con un huso; en esta versión en vez de morir, sólo caerá en un sueño profundo que durará cien años, al cabo de los cuales el hijo de un rey llegará a despertarla” (Hernández Cuevas y Zepeda Soto, “Galaor" a lomos, 38). En Galaor Sota de Espadas dice:

Terminada mi labor de cirugía y altísima costura, debo recordarles que Brunilda, pese a su apariencia de embalsamada o de monumento, está sólo dormida, y que si algún varón no mayor de treinta años ni menor de quince, realizare con ella cualquier acto de honesto y sincero amor, Brunilda volverá a la vida en los quince años de su edad y será bella y tierna como una manzana. Si el amor no se clavare en ella como mis agujas de costurera, permanecerá en su estado actual de admirable obra maestra de la taxidermia (Galaor, 18 y 20 ).

En varias versiones del cuento tradicional es a los quinces años cuando la joven se pincha el dedo, mientras que en Galaor desde bebé entra a ese estado, pero se estipula que cuando salga de él tendrá justamente esa edad. Además, en la novela de Hiriart, la belleza es algo que se obtiene hasta después de haberse roto el hechizo. Brunilda se convierte en un objeto embalsamado, es decir, en un cadáver que está vivo, en contraste con "La bella durmiente del bosque", que

\footnotetext{
${ }^{9}$ Se le otorgan otros cinco epítetos que hacen referencia a su estado: "La durmiente" (24, 34, y 99); "La santa dormida, disecada y sonriente" (25); "La niña disecada" ( 34 y 97), "La disecada” (39 y 97); y "La pequeña y dura durmiente disecada” (97).
} 
en algunas variantes da señales de que está viva aunque sólo duerme, siendo la más clara de éstas la versión de Basile en la que puede concebir en ese estado. Además "no se menciona puntualmente que sea el amor el que rompa el hechizo. Es ahí donde entra el ingenio de Hiriart, quien de forma paródica recontextualiza el texto de Perrault y agrega de manera cáustica el ingrediente del amor" (Hernández Cuevas y Zepeda Soto, "Galaor" a lomos, 38).

Otro elemento que es transformado es el lugar donde queda "La durmiente disecada”, pues mientras que en el cuento tradicional se le pone en el castillo, ${ }^{10}$ Hiriart le da una inversión carnavalesca, ya que en lugar de mantenerla protegida, los reyes la convierten en un espectáculo:

Don Grumedán y doña Darioleta, reyes del País de las Liebres, ordenaron la inmediata construcción de un pedestal para Brunilda, la durmiente disecada. El monumento, fabricado de alabastro amarillo, era esbelto simpleysu veteado rojo oscurolo recorría como fogata. Para que todos pudieran mirarla y la deseada transformación tuviese lugar, Brunilda fue colocada en el salón principal del palacio (Galaor, 22).

Se da una situación contraria a la del cuento tradicional en el que la joven comienza a ser olvidada con el paso de los años, Brunilda por el contrario "no fue olvidada: su fama divulgóse por el mundo y creció a superstición; de todas partes acudían peregrinos a admirar el portento, al que por oscuras convicciones algunos dieron en llamar 'La santa dormida, disecada y sonriente"” (Galaor, 24-25). Es decir, se mitifica a Brunilda, trasciende. Esta peregrinación hace que "Príncipes, reyes, duques, barones y caballeros de todos los reinos acudieron al País de las Liebres a contemplar a la durmiente disecada; unos codiciosos de las muchas riquezas del reino, otros con la esperanza leal de romper con amor el hechizo de la durmiente, algunos enamorados ya de la Brunilda de quince años fresca y bella como una manzana” (Galaor, 24).

Un último aspecto de la ficcionalización de Brunilda es que se le medievaliza por medio de un tópico propio de las novelas de caballerías: el de la dama que debe ser rescatada, dado que mientras los campeones están abatidos después de la aparentemente infructuosa caza del puerco del Automedonte, Brunilda es raptada, con lo cual

10 "Firent publier des défenses à qui que ce soit d'en approcher. Ces défenses n'étaient pas nécessaires, car il crût dans un quart d'heure tout autour du parc une si grande quantité de grands arbres et de petits, de ronces et d'épines entrelacées les unes dans les autres, que bête ni homme n'y aurait pu passer: en sorte qu'on ne voyait plus que le haut des Tours du Château, encore n'était-ce que de bien loin" (Perrault, "La belle",100).

Medievalia 49, 2017, pp. 87-100 
Hiriart ya se introduce en los terrenos de los libros de caballerías, y al aludirlos, se reconoce que es la mujer - o en este caso, la cosa que no deja de ser del sexo femenino- el motor de la aventura. "Brunilda la durmiente disecada desapareció de su pedestal [...]. Los soldados se mezclaron entre los bailarines y cantores: indagaban y buscaban" (p. 32). Todos los caballeros se pusieron en acción para buscar a la princesa, pero "don Famongomadán fue el más activo indagador $[\ldots]$ junto a sus criados todos mudos y sombríos, montó en Sardanápalo y partió a galope después de gritar: traeré a Brunilda viva o disecada" (Hernández Cuevas y Zepeda Soto, "Galaor" a lomos, 51-52).

Las palabras de Famongomadán, cuyo nombre nos remite a un gigante de Amadís de Gaula de Rodríguez de Montalvo, reflejan que no sólo se ve a Brunilda como la dama que debe ser rescatada, sino también como un objeto que debe recuperarse poniéndola, hasta cierto punto, al mismo nivel que el Santo Grial, por mencionar una búsqueda emblemática de la narrativa caballeresca.

En fin, el bautizo y la disecación de Brunilda son un claro ejemplo de cómo dos motivos tradicionales que forman parte de nuestro imaginario cultural, como lo son la entrega de los dones y el letargo de "la bella durmiente del bosque”, pasan por un proceso de reficcionalización medievalizante cuando son insertados en una obra caballeresca moderna, pero sin perder los elementos que lo anclan en el imaginario popular; en otras palabras, se trastoca a los motivos tradicionales, en este caso, al punto de parecer versiones macabras de aquéllos al hacer que los dones la conviertan en un monstruo y el letargo sea una disecación, pero no dejan de ser reconocibles y, en general, siguen teniendo los elementos que se esperarían de un relato tradicional, sólo que todo ello ajustado al mundo narrativo de la novela, el cual, como ya se ha dicho, está entre el cuento de hadas y la novela de caballerías. Por tanto, son un recordatorio más de que en Galaor

Las aventuras que se relatan, las características de muchos de los personajes, las descripciones de los paisajes, escenarios, fiestas y vestuarios, apuntan a la construcción de un ambiente feérico, de una geografía imaginaria, de un tiempo sin tiempo, de un mundo feliz, en suma, que se ofrece tal como podría esperarse de muchas novelas de caballerías y de todos los cuentos de hadas (Corral Peña, "La decepción”, 158). 


\section{BIBLIOGRAFÍA}

Bueno Serrano, Ana Carmen, Índice y estudio de motivos en los libros de caballerías castellanos (1508-1516), tesis doctoral, Zaragoza: Universidad de Zaragoza, 2007.

Bueno Serrano, Ana Carmen, "Aproximación al estudio de los motivos literarios en los libros de caballerías castellanos (1508-1516)", en Juan Manuel Cacho Blecua (coord.), De la literatura caballeresca al "Quijote", Zaragoza: Prensas Universitarias de Zaragoza, 2007, 95-113

Bueno Serrano, Ana Carmen, "Motivos folclóricos y caballerescos en los libros de caballerías castellanos”, Revista de Poética Medieval, 26, 2012, 83-108.

Calvino, Italo, “Tirant lo Blanc”, en Por qué leer los clásicos, Aurora Bernárdez (trad.), México: Tusquets, 1992.

Colón Hernández, Cecilia, Los elementos tradicionales y los símbolos profanados en "Galaor", tesina de especialidad, México: Universidad Autónoma Metropolitana-Azcapotzalco, 2001.

Corral Peña, Elizabeth, “Galaor: la decepción como sistema”, Anuario de Letras, XXXIX, 2001, 145-151.

GonzÁlez, Aurelio, “Galaor o la vehemencia de la perfección”, en Sergio Fernández (ed.), Ensayos heterodoxos, México: Universidad Nacional Autónoma de México, 1991, I 207-220.

Hernández Cuevas, Olga Lidia y Deyanira Zepeda Soto. "Galaor" a lomos de la intertextualidad, tesis de licenciatura, México: Universidad Nacional Autónoma de México, 2006.

Hiriart, Hugo, Galaor, México: Joaquín Mortiz, 1972.

Iser, WolfGAng, "La estructura apelativa de los textos", en Dieter Rall (comp.), En busca del texto. Teoría de la recepción literaria, Sandra Franco y otros (trad.), México: Universidad Nacional Autónoma de México, 2008, 99-119.

Luna Mariscal, Karla Xiomara, “Índice de motivos de las historias caballerescas del siglo XVI: catalogación y estudio”, en Juan Manuel Cacho Blecua (coord.), De la literatura caballeresca al "Quijote", Zaragoza: Prensas Universitarias de Zaragoza, 2007, 347-359

Luna Mariscal, Karla Xiomara, "Aproximación al estudio de las historias caballerescas breves a partir de los motivos folclóricos”, en José Manuel Lucía Megías y María Carmen Marín Pina (eds.), Amadís de Gaula: quinientos años después. Estudios en homenaje a Juan Manuel Cacho Blecua, Alcalá de Henares: Centro de Estudios Cervantinos, 2008, 457-469.

Luna Mariscal, Karla Xiomara, "Problemas teóricos y metodológicos en la elaboración de un índice de motivos folclóricos de las historias caballerescas del 
siglo Xvi”, en Lilian von der Walde Moheno, Concepción Company y Aurelio González (eds.), Expresiones de la cultura y el pensamiento medievales, México: El Colegio de México, Universidad Nacional Autónoma de México y Universidad Autónoma Metropolitana, 2010, 313-325.

Luna Mariscal, Karla Xiomara, "De la metodología o la pragmática del motivo en el índice de motivos de las historias caballerescas breves”, eHumanista, 16, 2010, 127-135.

Perrault, Charles, “La belle au bois dormant”, en Contes, edición de Gilbert Rouget, Paris: Bordas, 1991, 91-107. 